\title{
Is The Natural Step's Theory about Sustainability Still Sustainable? A Theoretical Review and Critique
}

\author{
Joshua D. Nathan ${ }^{1}$ \\ ${ }^{1}$ Organizational Learning, Performance and Change Program, Colorado State University, Fort Collins, Colorado, \\ USA
}

Correspondence: Joshua D. Nathan, 8500 E. Jefferson Avenue \#6F, Denver, CO, USA Tel: 1-303-358-7864.

E-mail: joshuadnathan@yahoo.com

Received: December 11, 2017

Accepted: December 19, 2017 Online Published: January 30, 2018

doi:10.5539/jsd.v11n1p125

URL: https://doi.org/10.5539/jsd.v11n1p125

\begin{abstract}
With sustainability initiatives attracting quality employees, many businesses concentrate more on their ecological imprint than on sustaining their human capital. Theories such as Karl-Henrik Robèrt's The Natural Step $(1997,2000,2002)$ prize a balance with the environment above one with people. Yet, an increasingly ageing workforce with increasingly common chronic diseases has led corporations to hemorrhage money-from direct costs because of absenteeism to indirect costs because of decreased productivity. Although eligible in many countries for accommodations, many chronically ill employees choose not to self-disclose, instead, masking their illnesses from employers. Questioning the sustainability of The Natural Step (TNS) from this perspective, this paper also critiques TNS' evolution as a theoretical construct through the lens offered by the General Method of Theory Building in Applied Disciplines.
\end{abstract}

Keywords: backcasting, chronic illness, framework for strategic sustainable development (FSSD), strategic planning, social sustainability, sustainability principles, system conditions, The Natural Step (TNS), theory building in applied disciplines, workplace wellness

\section{Introduction}

The Natural Step (TNS) is a veritable goliath when it comes to sustainability theories based on systems thinking (Malcolm, 1998; Robèrt, 2000; Robèrt et al., 2002; Waldron, Byggeth, Ny, Broman, \& Robèrt, 2004; Waldron, 2005). Since 1989, a somewhat modest scientific consensus on four core tenants of sustainable development (SD) has evolved into a vast transnational alliance of research organizations and nongovernmental resources. TNS offers public pedagogy as well as guidance in applying its Framework for Strategic Sustainable Development (FSSD), which comprises the theory's methodology. TNS' FSSD, however, should not be confused with TNS' conceptual framework of core system conditions that defines what it means to be ecologically and socially sustainable (Robèrt, 2000). As a theory, TNS has withstood increased scrutiny, to a degree, from scholars pointing out omissions as well as excluded aspects that are pertinent to today's organizations (Upham, 2000a; Missimer, Robèrt, Broman, \& Sverdrup, 2010).

\subsection{The Problem}

The Natural Step has not, nor was it ever intended to, relate sustainability initiatives to increases in productivity, performance, expertise, or efficiency (Robèrt, Daly, Hawken, \& Holmberg, 1997). Spearheaded by Swedish oncologist Dr. Karl-Henrik Robèrt in the late 1980s, TNS began in response to a call from a United Nations subcommittee to develop paths toward environmental sustainability (Brundtland, 1987). The core system conditions Robèrt established were designed to be as simplistic as possible to create an easily understood persuasive argument with an appeal toward wide application and, in particular, quick dissemination.

TNS was designed to "apply to situations that do not attempt to establish universal laws but go beyond describing single instances of human activity" (Swanson \& Chermack, 2013, p. 21), which classifies TNS as a midrange systems theory. Despite significant evolution, TNS is based on assumptions with embedded biases and has only recently added more social elements to its FSSD (Missimer et al., 2010). With the exception of serving as a conversation starter for champions of the "Green Movement", TNS' practicality is increasingly questionable as is its current relevance. 
Despite a focus on ensuring the survival of humanity in concert with business, an area TNS fails to fully address is propelling the health of the human species. According to Andrew Thatcher (2014), "Sustainable development is primarily a social justice project focusing on equitable development to meet human needs while still recognizing that the preservation of natural resources is necessary to fulfill these needs" (p. 747). TNS may initially appear to be borne from social justice. However, the theory does not address ties between the environment and the increasing numbers of chronically ill employees, which has evolved into a significant problem for corporations and countries alike during the past decade (Hoy et al., 2014; Munir, Randall, Yarker, \& Nielsen, 2009). This rise in diseases and disorders stems, to a large degree, from past ecological pollution:

Increased temperatures and disruption of ecosystems by climate change impact directly on health and on lung health in particular. Vector-borne diseases may worsen (as vector distribution, breeding and feeding patterns change), crop failure (from flooding, heat waves and extreme weather events) will drive starvation and cases of bacterial diarrhoea and exposure to toxic algal blooms will increase. Climate change can increase exposure to pollen and mould allergens. Raised temperatures increase concentrations of ground-level ozone and particulates. This impacts both the development and the severity of asthma, rhinosinusitis, COPD and respiratory tract infections. (Hopkinson et al., 2017)

TNS attempted to integrate social elements into aspects of sustainability in 2017 (Missimer, Robèrt, \& Broman, 2017a; Missimer, Robèrt, \& Broman, 2017b). But these revisions are too recent to determine their impact, especially considering that the theory's framework of system conditions still places a natural, and greater, emphasis on the latter two of the "3Ps: people planet and profit" (Ellison \& Nou, 2011, p. 40).

\subsection{Purpose of the Article}

TNS ignited a widespread debate about sustainability initiatives and offers helpful insight through its pedagogical concepts and hands-on tools (Burns, 1999). Many would currently argue, however, that, despite significant explication and refinement during nearly the past 30 years, TNS' latest iteration may or may not meet the needs of corporations that have largely understood the importance of workplace wellness programs during the past decade with widespread implementation and assessment:

Fifty-three percent of large employers polled in June and July 2015 by Towers Watson \& Co. and the National Business Group on Health say they use a variety of financial and nonfinancial metrics to some extent to better gauge their wellness programs' net impact on their businesses, including overall employee productivity, absenteeism rates and short-term disability costs. (Dunning, 2015, p. 4)

Some claim TNS' ecological bent is based on assumptions, limitations, and fallacies that naturally direct its focus significantly more toward overall organizational health with lesser concerns regarding the needs of individuals or employees (Thatcher, 2014). It does not address sustainability queries related to rising rates of illnesses among employees that lead to lower levels of productivity with high direct and indirect organizational costs ("Chronic conditions cause 164 million missed workdays, cost employers $\$ 30$ billion yearly,” 2007). Considering some of these omissions could stem from the theory's development:

The purpose of this paper is to critique TNS' evolution through the lens offered by the General Method of Theory Building in Applied Disciplines.

After TNS is examined through each phase of the General Method of Theory Building in Applied Disciplines (Lynham 2002; Swanson \& Chermack, 2013), the focus of this paper highlights deficient areas within TNS.

Furthermore, sustainability concerns involved in supporting, and maintaining, an efficient population of human capital have grown increasingly important considering employees are at the core of the viability of most modern companies (Swanson \& Holton III, 2009).

\section{Evolution of a Contributing Theory}

Since the late 1980s, American public attention began turning away from the green of its currency and toward the diminishing green of its agricultural landscapes. Those in other westernized countries were focusing on similar environmental issues (Brundtland, 1987; United Nations, 2015). From the dangers of water pollution, as toxic chemicals seep into aquifers, to detrimental health effects from consuming food covered in dangerous pesticides to measurable holes in the ozone layer from unhindered chlorofluorocarbon (CFC) emissions to lower $\mathrm{pH}$ values with higher concentrations of heavy metals in soil, empirical support to change the business processes mining the Earth's limited resources has steadily grown. 
Perhaps the most visceral and popularized depiction of directly inflicted environmental damage in the United States occurred on March 24, 1989, when the oil tanker Exxon Valdez struck Bligh Reef in Alaska's Prince William Sound (Holleman, 2014). The worst oil spill in U.S. history at the time, hundreds of thousands of animals perished with some species unlikely to recover despite extensive and expensive cleanup efforts in the water as well as along the more than 1300 miles of damaged coastline. "Even if we as a society don't care about oil spills destroying natural environments, we've got to care - eventually we will all care - about how burning this oil is destroying our environment through climate change" (Holleman, 2014).

As public attention continued to turn toward the environment, few knew how to proceed to best balance economic opportunity and growth with ecological responsibility. In that vein, the United Nations had already established the World Commission on Environment and Development (WCED) to determine common goals.

\subsection{World Commission on Environment and Development (WCED)}

Increasingly concerned about detrimental environmental ramifications stemming from common business practices, the U.N. tasked the WCED with translating the broad ideas behind the evolving "Green Movement" into a statement about sustainability that could be embraced by most organizations at a foundational level. There were no pre-specified limitations confining the WCED's focus solely to ecological sustainability. In fact, in its final report, the WCED specifically noted such limitations would have been detrimental to its mission:

When the terms of reference of our Commission were originally being discussed in 1982, there were those who wanted its considerations to be limited to "environmental issues" only. This would have been a grave mistake. The environment does not exist as a sphere separate from human actions, ambitions, and needs, and attempts to defend it in isolation from human concerns have given the very word "environment" a connotation of naivety in some political circles. The word "development" has also been narrowed by some into a very limited focus, along the lines of "what poor nations should do to become richer", and thus again is automatically dismissed by many in the international arena as being a concern of specialists, of those involved in questions of "development assistance". (Brundtland, 1987, pp. 6-7)

What followed from this report could be characterized as a period of strife in developing business models more ecologically mindful that were still very mindful of profit, a primary corporate goal. To this day, the WCED provides "the most widely cited definition [describing] sustainable development. . .." (Thatcher, 2014, p. 748) and led to the basis of The Natural Step as well as other theories about sustainability.

\subsection{Confusion}

Theories about how to achieve the WCED's vague definition of sustainability vary in both purpose and impact. A working definition of a generalized state of "sustainability" emerged from these contexts, now cited in a motley of journal papers:

Sustainability is a relationship between dynamic human economic systems and larger dynamic, but normally slower-changing ecological systems, in which: (1) human life can continue indefinitely, (2) human individuals can flourish, and (3) human cultures can develop; but in which effects of human activities remain within bounds, so as not to destroy the diversity, complexity and function of the ecological life support system. (Costanza, Daly, \& Bartholomew, 1991, p. 1)

These goals engaged both scholars and practitioners alike when it came to views of sustainability. Yet, few knew not only the best way to reach it, but also how to convince businesses that suggested approaches were in their best interests too.

\section{Method}

In order to analyze TNS as a theoretical contribution, the General Method of Theory Building in Applied Disciplines (Lynham, 2002; Swanson \& Chermack, 2013) is utilized: 


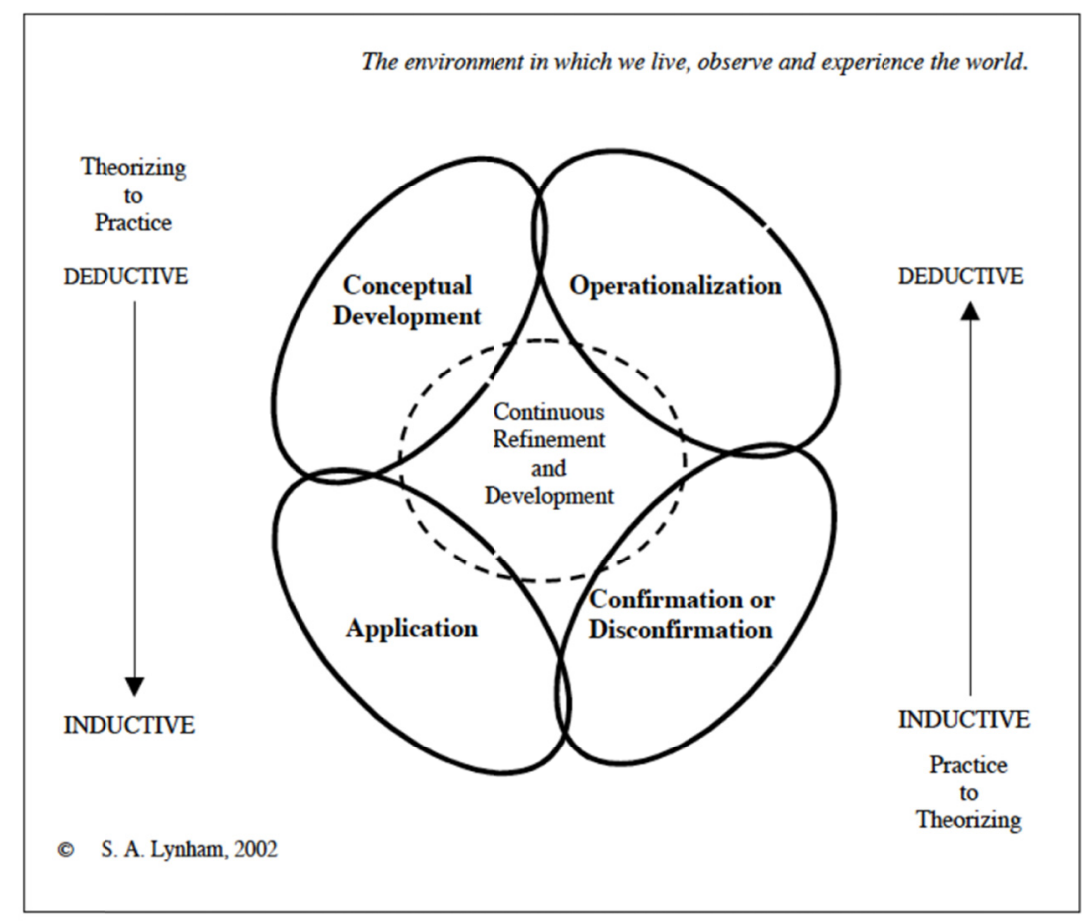

Figure 1. The general method of theory-building research in applied disciplines

Adapted from "The General Method of Theory-Building Research in Applied Disciplines" by S. A. Lynham, 2002, Advances in Developing Human Resources, 4(3), p. 231. Copyright 2002 by S. A. Lynham.

While a theory can begin in any phase of the theory building process, the phases represent a cycle that, once fulfilled, lead to a mature theory:

...[I]deas by themselves do not constitute theory. Inquiry studies by themselves do not constitute theory. The development of an assessment instrument by itself does not constitute theory. . . . From our point of view, theories are ideas that have been translated to assessment criteria, confirmed in rigorous inquiry studies, applied in practice, and are subjected to ongoing assessment and examination. (Swanson \& Chermack, 2013, p. 174)

The four phases of theory building include: 1) The Conceptualize Phase in which the identified individual concepts are discussed and described based upon their relationships with one another, leading to a model with clear boundaries; 2) The Operationalize Phase defines how the theory can be measured and assessed; 3) The Confirm Phase moves the theory into practice to prove or disprove functionality; and 4) The Apply Phase assesses a theory's widespread applicability in real situations.

Once these first four phases are complete, a fifth phase, The Refine Phase, begins. It never concludes and involves an open forum for others to critique, analyze, and assess the theory, inviting further theoretical clarification or elaboration. The refine phase is perhaps the most important phase in the further evolution of a theory, as "[c]ontinuous refinement of an applied theory is a process keeping the theory under the microscope" (Swanson \& Chermack, 2013, p. 122). Thus, theory building is a never-ending process when it comes to further refinement despite an initially robust theory that, ideally, emerged from the first four phases of development.

\subsubsection{The Natural Step (TNS)}

TNS began with Robèrt's end-state sustainability criteria embedded in his final document presented to the Swedish King in 1989. Almost simultaneously, physicist John Holmberg began developing a model that could guide any organization toward reaching Robèrt's end-state criteria. Yet, before Holmberg's methodology was complete in 1997, TNS entered into its confirm and apply phases with Swedish organizations adopting its core system conditions. While not ideal, these phases may naturally overlap given certain conditions. However, when viewing the TNS as a theory, it progressed through all four primary phases within the span of merely one decade - leaving many to refine it during the 20 years that followed. Those refining TNS' FSSD included Robèrt 
who, in conjunction with other authors, provided a series of journal publications in 2017 that expanded his original core system conditions to take into account social systems.

\subsection{The Conceptualize Phase}

"We are at a point now where we need to renegotiate the rules of our economic game so that they conform to the rules of the biophysical world which cannot be amended, changed or negotiated" (Robèrt, Daly, Hawken, \& Holmberg, 1997, p. 80). In part, an ecological crisis of conscience had only emerged in the public sphere a decade earlier. Once bolstered by the U.N.'s Brundtland Report (1987), western populations seemed poised for change. Despite a vague and qualitatively driven call for ethical environmental responsibility, the Brundtland Report's definition of sustainable development is still one of the most widely cited in today's literature: "Humanity has the ability to make development sustainable to ensure that it meets the needs of the present without compromising the ability of future generations to meet their own needs" (Brundtland, 1987, p. 16). These issues prompted academics and practitioners to develop widely applicable solutions of which some, like TNS, emerged as theories.

TNS is grounded in "first order principles for ecological, economic, and social sustainability for the whole ecosphere" (Nattrass \& Altomare, 1999, p. xv). Its four system conditions are derived from the unwavering scientific proposition that nature cannot withstand a quick buildup or extraction of fossil fuels and other atmospheric contagions. These principles address the economic and ethical consequences when land resources dwindle because of anything from agricultural rape to impoverished people living in overpopulated, contaminated areas.

\subsubsection{Consensual Scientific Agreement}

Understanding the cellular nature of the human body and their changes with cancerous growths, Robèrt sensed a similar relationship when it came to sustainable development. "It hit me that cells are the unifying unit of all living things. . . . Since politicians and business people are constituted as cells, I had a feeling that a broad understanding of these cells might help us reach a consensus on the basic requirements for the continuation of life," Robèrt (1998) said in a video clip posted on The Natural Step International's website.

To distill applicable principles, Robèrt disseminated a paper to approximately 50 scientists in a bid for consensual agreement when it came to the core system conditions necessary for sustainable development. After many drafts, agreement emerged with four core system conditions:

In the sustainable society, nature is not subject to systematically increasing

I. Concentrations of substances extracted from the Earth's crust

II. Concentrations of substances produced by society

III. Degradation by physical means and, in that society ...

IV. People are not subject to conditions that systematically undermine their capacity to meet their needs.

(Ny, MacDonald, Broman, Yamamoto, \& Robèrt, 2006, p. 64)

While Robèrt and others would revise the conditions, these four comprised TNS' principles that essentially persisted for decades. If a business met these conditions, it meant it was sustainable from TNS' perspective and could continue operations knowing it was causing no harm to the environment or logistical impediments to the future development of humanity.

\subsubsection{TNS' "Funnel" Framework}

In organizing the conditions, Robèrt considered them extensions of well established laws of nature that provided a "minimum requirement for sustainability" in which the economy was a "subsystem of the ecosystem at each scale", people did not have to act against their self-interests, was simple enough to teach to a wide audience, contained realistic goals for industry to reach without large-scale change, and did not create an adversarial relationship when implemented (Robèrt et al., 1997, pp. 88-90). The four conditions were designed to interrelate but not overlap. 


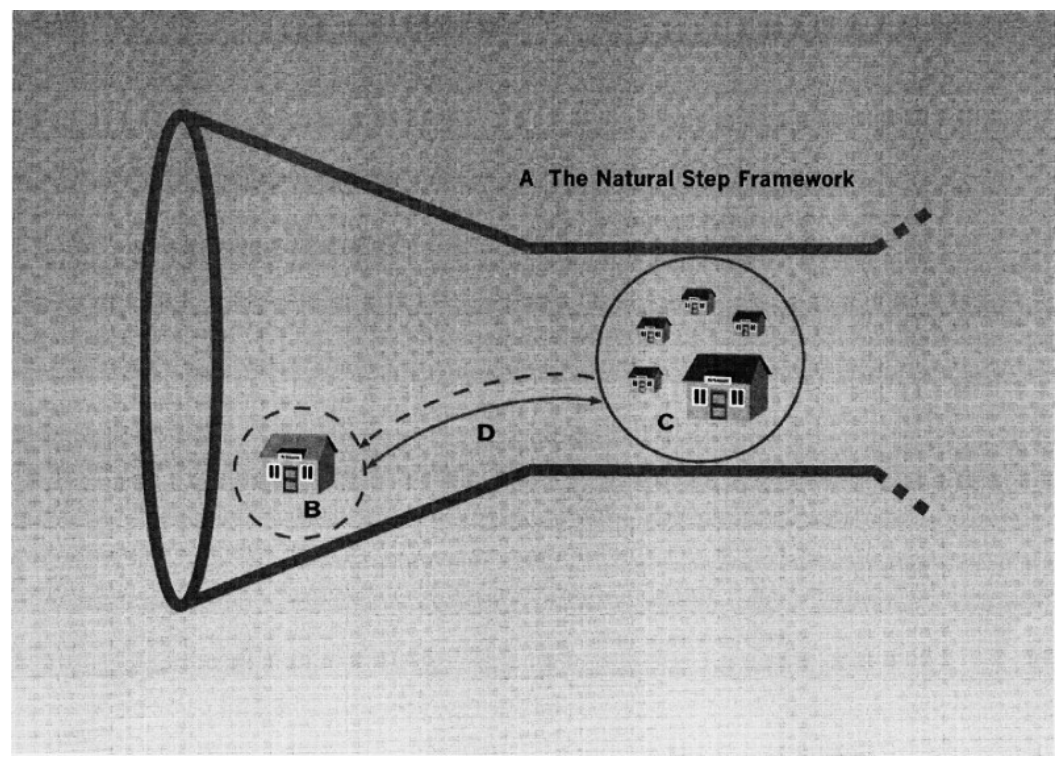

Figure 2. The Natural Step Framework: "The Funnel"

A feedback loop encompassing system conditions was represented through the following steps: (A) Referred to the model's visual translation of system conditions; (B) examined present operating conditions negatively affecting the first three system conditions; (C) focused on brainstorming ways to alter practices adversely affecting the environment within the context of the first three system conditions; and (D) illustrated a new design that did not violate system conditions. Adapted from "Tools and Concepts for Sustainable Development, How Do They Relate to a General Framework for Sustainable Development, and to Each Other?" by K.-H. Robèrt, 2000, Journal of Cleaner Production, 8(3), p. 246. Copyright 2000 by K. -H. Robèrt.

In TNS' funnel-like framework, the first three conditions were depicted at the funnel's wide conical mouth as functionally different mechanisms that, combined, allowed humanity to flourish. Robèrt depicted emissions as flowing toward the funnel's mouth from its narrower stem in which homes were housed (1997). They represented centers of population and industry. Robèrt's analogy to a funnel illustrated that, with increased ecological problems, the funnel's mouth would need to grow proportionally wider (Robèrt et al., 1997). The depiction of homes in the stem represented the fourth condition because it was the main element affecting the three system conditions at the funnel's mouth, which were hierarchically ordered.

An implication arose that the fourth system condition incorporated a social element. However, it did not relate to meeting human needs from a sociological perspective. Instead, it appeared solely as the base product, humans, who either supported or destroyed the funnel (i.e. the ecosphere and its biodiversity). Robèrt also discussed that humans comprised the fourth system condition to indicate their role in self-survival as well as the ability of the planet to sustain that survival. He wrote, however, that humans needed to prioritize collective self-preservation above individual preferences or desires, all of which he dubbed a "luxury" (Robèrt et al., 1997).

Robèrt then bounded his four system conditions by relevant aspects found in the corresponding ecosphere. He clearly enumerated them, implying they were all scientifically proven and not open for dispute or debate. They were knowledge claims:

(a) the principle of matter conservation, (b) the laws of thermodynamics, (c) the principles of the sundriven biogeochemical cycles, (d) the fact that the biosphere cannot sustain systematic shifts of its physical parameters (lower and lower $\mathrm{pH}$, higher and higher concentrations of $\mathrm{NO}_{\mathrm{x}}$, smaller and smaller areas for renewable resources, etc.), and (e) society's dependence on sustainable resource flows and services from the ecosphere. (Robèrt, 2000, p. 248)

TNS involved both its funnel-depicted framework of system conditions and its Framework for Strategic Sustainable Development (FSSD), which was mainly developed during the next theory building phase.

\subsection{The Operationalize Phase}

This phase in theory building involves describing propositions and empirical indicators as well as hypotheses. In this respect, there was an overlap between TNS' conceptualize and operationalize phases. To begin to construct 
TNS' four system conditions, Robèrt, with input from Holmberg, examined ways humans were destroying the functions and biodiversity of the ecosphere. To translate these ideas into system conditions, the two added a negation to the destructive tenants. Then they invited other scientists to agree or disagree with a list of identified practices that should be avoided.

Ending systemic increases destroying the environment provided guidance for TNS' backcasting methodology after what appeared as undeniable empirical indicators that "...waste is steadily accumulating and resources are steadily diminishing. This means the resource potential for health and economy is systematically decreasing" (Robèrt et al., 1997, p. 87). Scientific investigation into environmental degradation was unanimous when it came to some of the accumulating damage. The extent to which that damage could be reversed or changed was not unanimous and still is not today. "For example, human-created flows of aluminum are relatively insignificant compared to aluminum's abundance in nature, whereas human-created flows of lead are twelve times that of naturally occurring flows" (Burns, 1999, p. 338). Thus, the hypothetical product in this phase was that change, with specificity to TNS, was a moral imperative (Robèrt et al., 1997). During this same time, Holmberg was developing backcasting-TNS' primary tool designed to guide companies and cities craving sustainable development.

\subsubsection{Backcasting}

First coined by John Robinson when working with energy futures in 1987, Holmberg borrowed the term "Backcasting" as the basis of developing this part of the TNS' Framework for Strategic Sustainable Development (FSSD):

[It] is based on a description of conditions for sustainability in the whole ecosphere, highlights the need for those more specific tools, and can be helpful in coordinating those to the benefit of the whole. Hence, the conditions for sustainability presented . . . can be used to guide specific tools for sustainable development. (Holmberg \& Robèrt, 2000, p. 4)

The methodology specified that an organization start planning how to meet a state of ecological sustainability by exploring the gap between its current system of doing business and that which would allow it to meet the four end-stage sustainability conditions established by Robèrt. Organizations begin by upstream thinking: "Problems are attacked by focusing upstream in cause-effect chains, i.e. measures are taken to remove the underlying sources of problems rather than to 'fixing' problems once they have occurred" (Robèrt, 2000, p. 244). Backcasting is the next step.

In working to "predict the future from today's trends (traditional forecasting), one also tries to liberate beliefs about today's situation and to understand what requirements and possibilities sustainability will involve in the future" (Holmberg, 1998, p. 30). Holmberg argued backcasting had proven superior to forecasting when society faced complex problems even though some stemmed from dominant societal practices and entailed a long timeframe to emerge to full detrimental fruition.

Developing a shared mental model of sustainability for an organization became an important step in TNS, as organizations examined their practices with respect to the four system conditions. Holmberg claimed funding for sustainable strategies was often assessed through traditional economic metrics focusing on whether change would lead to an increase in future profits. Holmberg expressed the relationship through the following equation:

$\mathrm{I}=\mathrm{i} x \mathrm{~m} x \mathrm{u} x \mathrm{P}$ where $\mathrm{I}=$ impact in nature; $\mathrm{i}=\mathrm{I} / \mathrm{M}$ (impact/energy and material flow); $\mathrm{m}=$ $\mathrm{M} / \mathrm{U}$ (material and energy flow/utility, service); $\mathrm{u}=\mathrm{U} / \mathrm{P}$ (utility or service/population); $\mathrm{P}=$ population. . . . The equation illustrates the dilemma facing humankind - the double challenge inherent in the concept of sustainable development: to develop and reach an acceptable quality of life from material and energy flows for a growing population; and, in parallel, to decrease society's harmful physical impact. (Holmberg, 1998, pp. 40-41)

Once specific materials, processes, corporate missions or values were identified as impediments to change, it became a matter of altering those elements - from levels of raw materials to strategic and value judgment changes engendered by guiding constituents.

TNS did not emerge with specific metrics to test in this phase, as might otherwise be common. Metrics were described qualitatively, as different businesses required different metrics based on different damaging environmental outputs from their work. "Activities and metrics are to be individually chosen and designed for particular situations or projects in line with the framework" (Robèrt et al., 2002, p. 250). Hence, there was no homogenized set of metrics, nor was there ever intended to be, in TNS. 


\subsection{The Confirm Phase}

According to Swanson and Chermack (2013), "The confirm/disconfirm investigation has features similar to most inquiry strategies - planning, design, implementation, and evaluation" (p. 95). However, Holmberg, in his paper on operationalizing TNS through backcasting, mentioned there was little to study in what would normally be a theoretically driven confirm phase test of TNS at a veritable company. TNS had already been adopted by more than 60 companies throughout Sweden. Instead of a specific confirm phase test, both Holmberg and Robèrt studied the documentation at organizations using TNS. This tactic was, by no means, the same as using a controlled study under rigorous conditions, which could have yielded far-reaching results, strengthening TNS as a theory.

However, borne as the product of choice — quick dissemination — neither theorist had any other option during this phase (Robèrt, 2000). While both theorists highlighted different companies in different articles, the Swedish people were known as collectively conscious of environmental problems based on influences from the 1962 book Silent Spring by Rachel Carson. Still, "Sweden was not congenial to the development of The Natural Step because of the conformity in the Swedish industrial sector reinforced by a relatively small number of powerful companies and a relative lack of entrepreneurial spirit" (Bradbury \& Clair, 1999, p. 64). Therefore, one must view early and successful case studies from that background rather than one indicative of how well TNS worked outside of Sweden.

\subsubsection{Interface's About-face}

One company consistently highlighted as an early case study proving TNS functioned as hypothesized was that of carpet manufacturer Interface. Founder and former CEO Ray Anderson proposed an about-face in Interface's practices to be facilitated through its new Environmental Task Force, the formation of which was announced on August 31, 1994. Anderson said it would transform the 21 -year-old company into “...the company that, by its deeds, shows the entire world what sustainability is in all its dimensions: people, process, product, place and profits - and in doing so, become restorative through the power of influence" (Anderson, 1994). By 2013, Interface reported using 49 percent recycled or bio-based materials in its carpet with an internal estimated savings of $\$ 450$ million (“The Interface story," 2016). It reduced its previously largest detrimental environmental impact -in its Production Stage Carbon Footprint - by 35 percent since 2008, which was when Interface implemented a new measuring system. Since 1996, the company estimated a total reduction of about 50 percent.

With guidance from TNS' four system conditions, the former head of Interface's Environmental Task Force reflected on how challenging it was to find and follow a methodology that would help direct the company toward change. "People don't realize that it took five or six miracles to get this far; Interface has always been in the miracle business," said Interface's initial head of the task force, Jim Hartzfeld (Davis, 2014). By 2015, 84 percent of all of Interface's manufacturing energy came from renewable sources. TNS considered Interface a coup, although not yet in a state of sustainability and, at least initially, not applying TNS' backcasting methodology that had yet to be fully formed when the carpet company began its journey.

\subsection{The Apply Phase}

Robèrt finished the four end-stage system conditions in 1989, aiming to make them as simplistic as possible for the widest possible application and dissemination, with public pedagogy a foundational part of his mission (Robèrt et al., 1997). This tactic tremendously limited any potential for development in the apply phase of the theory building process. While based on physics and a growing degree of scientific consensus, Robèrt (1997) even went as far as to write that many scientists did not understand how to apply or explain scientific principles to the businesses community let alone their importance to the voting public. He and Holmberg felt they could bridge that divide through TNS.

Robèrt's system conditions emerged solely from discussions among, and between, scientists. They were based on the first and second laws of thermodynamics, including the principle of matter conservation. After reaching scientific agreement in his $22^{\text {nd }}$ draft of system conditions required for sustainability, Robèrt presented his paper to the King of Sweden, Carl XVI Gustaf, who endorsed it. Thereafter, TNS was positioned as a politically and scientifically vetted model capable of adoption in any organization despite that, at the time, no methodology had been developed to guide its application. By jockeying for TNS' immediate attention, Robèrt eclipsed an ability to let TNS fully evolve as a robust and well-tested theory with broad-based utility when viewed through the lens of the General Method of Theory Building in Applied Disciplines (Lynham, 2002; Swanson \& Chermack, 2013).

With "60 corporations and over half the towns in Sweden" (Malcolm, 1998, p. 5) using TNS after the King lent his support, significant limitations paved the way during TNS' apply phase - not the least of which was that the 
system conditions were the sole agreement from a small sample of scientists. "Over the last twenty years, a group of scientists, including some of the authors, have explored the possibility to develop a framework based on backcasting from sustainability principles. This framework has since been elaborated and refined in theory as well as practiced in many organizations and sectors" (Missimer et al., 2010, p. 1108). In this 2010 paper, even Robèrt felt TNS was refined enough to consider and label it "theory".

\subsection{Theory Refinement}

While TNS sought more input from a wider array of scientists across Europe and North America, the first in a two-part series of journal papers in 2017 noted that "...the social dimension of this framework has not been found to be sufficiently science-based and operational and thus in need of further development" (Missimer et al., 2017a, p. 32). To address it, literature reviews were performed that led to a substantial revision in TNS' final system condition. The core principles that dominated TNS for nearly 30 years changed to an archetype characterized by the bio-economy, focusing on renewable resources and natural processes as well as societal issues:

In a sustainable society, nature is not subject to systematically increasing:

1. concentrations of substances extracted from the Earth's crust (e.g. fossil carbon, metals),

2. concentrations of substances produced by society (e.g. nitrogen compounds, endocrine disrupters),

3. degradation by physical means (e.g. large scale clear-cutting of forests, over-fishing), and in a sustainable society people are not subject to structural obstacles to

a. health (e.g. dangerous working conditions, insufficient rest times),

b. influence (e.g. by suppression of free speech, neglect of opinions),

c. competence (e.g. by obstacles for education, insufficient development options),

d. impartiality (e.g. by discrimination, unfair treatment) and

e. meaning-making (e.g. by suppression of cultural expression).

(Zimek \& Baumgartner, 2017, p. 14)

While significant peer or external pressures could have been the basis of this recent revision, it is too new to determine its effectiveness. It also continues to place human health in the lowest portion of the system conditions hierarchy.

Furthermore, none addresses the rising chronically ill working population mainly unidentified to employers (Paton, 2014). To some extent, these types of gaping theoretical holes would usually have been addressed during a theory's confirm and apply phases. "After having studied how social sustainability has been dealt within the FSSD (Missimer et al., 2010), these two tandem papers contribute to the solution prototype of a new approach to social sustainability within the FSSD and therefore are mainly characterized by theory building" (Missimer et al., 2017a, p. 34). Relegating nearly all of TNS' FSSD development to a significantly reactive and elongated refinement phase prompts a logical question: Were Robèrt and Holmberg aiming for a comprehensive theory or a comprehensive business?

\section{Discussion: Good Theory or Good Business?}

TNS offers an insightful perspective aimed at students as much as businesses. Even Robèrt (2000) admitted that "the relatively fast dissemination of [The Natural Step] framework in policymaking, and in the environmental debate, has led to a number of misunderstandings" (p. 244). Robèrt, Holmberg, and others continued to further develop the underpinning concepts guiding TNS while, at the same time, responding to critics.

\subsection{The Natural Step International (TNSi)}

As refinements were made to TNS, one might naturally wonder the lag time before those changes reached The Natural Step International (TNSi). Registered as a non-profit in Sweden, TNSi's main purpose is "to accelerate the transition towards a truly sustainable global society" by working with individuals and organizations to facilitate change aimed "to take concrete action towards, and beyond, ecological, social, and economic sustainability" (Ezechieli, Ugas, \& Aanraad, 2017, pp. 1-2). In many ways, TNSi acts as a brand manager for TNS through its 11 member offices with officers for the 2017-18 year living on five different continents.

Despite TNSi's non-profit status and website promoting public pedagogy, it offers services ranging from guest speakers to facilitators hired to help organizations transition through any portion of TNS. Yet, pages on its website about its "Sustainability Science" were missing for much of 2017, hampering genuine transparency and 
information. No unified price listing for services could be found. The same was true for documents indicating payments to speakers or facilitators.

According to its 2017 Statutes, TNSi's funding only comes from membership fees, donations, and grants. However, membership fees alone are generated "pursuant to TNS Licence Agreement" (Ezechieli, Ugas, \& Aanraad, 2017, p. 4) and change yearly at the Annual General Meeting. The most specific information about these fees stated "an emphasis on keeping the level of investment at the absolute minimum prudent level required to support the work" of the TNSi (Ezechieli, Ugas, \& Aanraad, 2017, p. 4). If TNSi was designed as an altruistic extension to expand TNS' reach, one might question these membership fees considering potentially sizeable grants. If designed with an aim toward good business, one might question the rationale behind Robèrt's extensive claims that following TNS is tantamount to a moral imperative.

\subsection{Biases and Fallacies}

TNS evolved into a global network through The Natural Step International (TNSi), which further blurred the lines between science, economics, and public policy—one of TNS' most distinguishable limitations. A primary bias is toward science and the related fallacy of absolutism. Robèrt repeatedly and consistently wrote that all physicists accept the first and second laws of thermodynamics as indisputable principles, which may or may not be true as scientists are consistently in the process of discovery. The implication, however, is that these laws are immutable and objective, which risks scientism. In addition, TNS does not explain how its core system conditions directly relate to thermodynamics and axiomatic physics, making the links interpretative from a constructivist paradigm.

TNS never specifies which biosphere contaminants must not increase. Instead, all should decrease or, based on TNS' system conditions, society moves away from sustainability. Again, this proposition suffers from absolutism and applies its broad system conditions equally to every location on the planet, which hampers utility. "TNS theory does not say what these breached thresholds are in terms of level or type; nor does it present evidence for their breach" (Upham, 2000a, p. 447). Even a move toward supplanting contaminants with new materials is forbidden under the system conditions if the result leads to a short-term rise in contaminants, placing strong boundaries on innovation and natural evolution despite TNS' claim that it increases innovation. "The stone, iron, bronze, agricultural and industrial revolutions in human history would not have been possible had the TNS systems conditions and [its] first intended corollaries been adhered to" (Upham, 2000a, p. 449). TNS advocates progress while restricting many paths toward it—particularly in growing economies. It poses a paradox.

\subsection{Limitations}

Robèrt voiced little faith in the ability of a "voting public" to understand anything complex, which drove him to forge simplistic system conditions in TNS (Robèrt et al., 1997). Without specific metrics, TNS also appears more akin to a persuasive argument rather than theory when it comes to strategic sustainability. TNS' proponents claim that its tools are applicable to any corporation and municipality on Earth (Missimer et al., 2017a). But it most clearly caters toward westernized, wealthier countries. The theory lacks context or an area for developmental space to explore alternatives in industries still reliant upon methods or materials that cause environmental degradation. "Inevitably, corporate progression to this end-state requires progression through intermediate stages, and that progression will involve breaching TNS' systems conditions" (Upham, 2000a, p. 449). Even backcasting contains implicit value judgments that, like other elements of TNS, may not be revered by all societies or functional in all contexts.

The organizations that adopted TNS in the 1990s were subject to immense limitations in using a partially constructed theory that avoided confirm and apply phases from the General Method of Theory Building in Applied Disciplines. Robèrt and Holmberg conscientiously risked progressing with their theory too quickly rather than waiting to fully construct it. Had they waited, in their eyes, they would have further added to the growing buildup of ecological contaminants. "[S]ince change in this case is necessary, there is also a risk in doing nothing" (Holmberg \& Robèrt, 2000, p. 9).

\subsection{Strange Appeals}

During the same timeframe, former British Prime Minister Margaret Thatcher was working in the United Kingdom on environmental sustainability initiatives. Once the FSSD emerged through TNS, the methodology seemingly showed any organization how to lower its carbon footprint without crushing its bottom line and was rapidly embraced. Add political influence through the Swedish King pushing TNS as a solution and one can see how TNS grew faster in practice than it did, or even could, through further theoretical refinement.

Governments might have been motivated toward ecological sustainability efforts whether they made for good 
business or not. Once supported by King Carl XVI Gustaf, though, both Robèrt and Holmberg more easily appealed to all communities in adopting TNS. Rather than a reliance on proven research linking TNS with long-term environmental and economic gains, Robèrt and Holmberg sought acceptance of TNS through an emotional, moral plea to C-suite executives. Guiding that somewhat irrational appeal was the assumption that TNS offered ethical ecological guidelines. By following TNS' core principles, a company was purportedly illustrating its ethical backbone even if its practices did not alleviate undue strain on the environment, which could easily lead to a post hoc fallacy. Adding to this argument was the notion that TNS led adoptees "to avoid unnecessary costs today and in the future" (Holmberg \& Robèrt, 2000, p. 8). Yet, without evidence, to support this assertion seemed like an idyllic sales pitch.

Robèrt and Holmberg (2000) continued to claim that "it is obvious that the chances for the individual polluter to avoid his or her individual economical responsibility will decline over time, as long as the decline in resources and assimilation capacity leaves less room for maneuver" (p. 8). Again, this rhetoric sounded plausible but was grounded more in politics and personal ethics than economics, resource pollution, and practicality.

\subsection{Limited Social Expansion}

As a sustainability theory, TNS still emphasizes ecology over people. "It should also be pointed out, again, that social sustainability does not mean that all people, or 'as many as possible', will be healthy or influential, or competent, etc. The principles are about whether or not power and norms imply obstacles to health, influence, competence, etc. The term 'structural obstacles to...' is key to each principle" (Missimer, Robèrt, \& Broman, 2017b, pp. 49-50). When discussing an "acid-test" for whether a social practice is "right" or "wrong", empathy was suggested to discern the answer even though it is not part of TNS (Missimer et al., 2017b, p. 50). With empathy largely open to valuation, it would seem TNS' FSSD only appears to expand when it comes to its previously missing social aspects.

In no part of this refinement does TNS take into account the largely unknown future as to how people will continue to work in an age when the causes of rising illnesses are still not fully understood by scientists - the very same people to whom Robèrt went for unequivocal support of TNS' system conditions. Scientists may have hypothesized that links between atmospheric contagions would naturally lead to greater numbers of chronically ill. But TNS failed to address this aspect or account for it, providing another post hoc fallacy applicable to its core system conditions.

“...TNS' environmental rather than social focus means that those who emphasize both of the latter aspects of sustainability may find that TNS does not adequately represent their concerns" (Upham, 2000b, p. 187). In the past decade, the number of those with chronic illnesses or disorders has risen dramatically, making a social component relevant and important to TNS. Otherwise, the theory seems ill suited to meet the future needs of humanity, as employees with the most prevalent health conditions - the majority of whom are "invisible"- continue to take their toll on organizations worldwide.

\subsection{Invisible Illnesses}

Low back pain (LBP) is a leading cause of workplace absences. The Global Burden of Disease 2010 Study culminated after six years of researching individuals in more than 180 countries. It reported that LBP affected nearly one in 10 people worldwide - a number expected to rise (Hoy et al., 2014) with an aging workforce in which corporate interventions tend to be more reactive than proactive.

LBP, like many inflammatory disorders and autoimmune diseases, indirectly costs businesses an estimated $\$ 1.1$ trillion annually ("Is a healthy work force in danger of disappearing?," 2012) because of its relationship to chronic pain that often goes unnoticed unless employees choose to disclose it. These indirect costs, which would be outside TNS' boundaries, emerge not only from decreased productivity due to discomfort or pain, but also from the hiring and training of temporary replacement employees. Direct costs from the chronically ill, however, are within TNS' boundaries and include costs related to increased absenteeism.

Whether the rising rates of disease and disorders stem from pollution already released into the biosphere, poor labor conditions in developing nations, or misunderstood phenomena, a secondary, but related problem, is how to best help these employees when the majority are unknown to their employers-avoiding self-disclosure to keep their maladies private given fear of stigmatization or ostracization (Paton, 2014). This population only enters TNS' recipe for sustainability in its fourth and lowest rung of core principles - a series of related social principles also designed to support the first three dealing solely with ecology.

\subsection{Rising Illnesses with Direct Costs}

The American Hospital Association (AHA) found that those with the three most common types of chronic 
illnesses, asthma, diabetes, and hypertension, collectively cost employers $\$ 30$ billion from lost work time. Direct costs from diabetes-affected employees alone reached $\$ 2.8$ billion in 2007 ("Chronic conditions cause 164 million missed workdays, cost employers $\$ 30$ billion yearly," 2007), costs that are expected to rise regardless of the malady.

In the United Kingdom, Dr. Natalie Jane Macdonald (2009) noted, "For the first time, we have a clear picture of the major health issues that will affect British workers over the next 20 years." She continued that chronic disease would pose "a serious threat to the productivity of British businesses by 2030" ("Ageing staff pose long-term threat to productivity levels," 2009).

Many chronic illnesses are relatively invisible to colleagues and employers unless there is a severe and visible flare in the workplace:

I live with primary adrenal insufficiency. For the most part, my disease is completely invisible [emphasis added]. You might see me always carrying a bottle of water with me, and I do wear a cortisol pump, but other than those two things, you would have no idea the gland responsible for the stress response in my body is completely dead. (Nicole, 2015)

Nicole discussed her awareness of jokes made about her work ethic, or seeming lack thereof, given her illness-related fatigue and the challenge of keeping up with her job as well as her doctors.

Nicole is also like many chronically ill employees. Whether based on company culture or simply because individual symptoms have yet to be medically tied to a specific disease, many mainstream job candidates, as well as workplace employees, tend to avoid self-disclosure and keep their maladies private (Paton, 2014). Although autoimmune diseases are still somewhat misunderstood by the public (Dellwo, 2016), the body's inflammatory response is a common characteristic transcending other chronic ailments that involve inflammation translating into pain. The resulting pain affects suffering employees in the same way as pain based on a different disorder or disease: lower workplace productivity and effectiveness with direct and indirect costs incalculable at the present time (Siu, Hung, Lam, \& Cheng, 2013). While some corporations consider not making adjustments to help the chronically ill population in the workplace, most employ some sort of wellness program because of long-term cost savings. The increasing number of employees with types of chronic illnesses "are typically treatable and less expensive in the early stages, but are often irreversible and expensive later" (White, 2015, p. 69).

\subsection{Sustainable Workforces}

Ramifications from chronically ill employees on workplace productivity, as well as on their own personal healthcare, prompted the formation of, and initiatives supported by, the European Network for Workplace Health Promotion (ENWHP). In describing its mission since its establishment in 1996, ENWHP infused ideas from the specific perspective of an organization's human capital and drew an analogy to illustrate applicability:

Shareholder value emphasises profit for the shareholders as the most important goal for a company. However, since corporate social responsibility, investing in quality at work and workplace health promotion are essential for business success, one could easily argue that this corresponds with optimising the shareholder value in a longer-term perspective. (De Greef \& Van den Broek, 2004, p. 13)

Considering TNS purports to incorporate the most basic levels of "corporate social responsibility", as described by De Greef and Van den Broek in 2004, a key question nearly 15 years later relates to the success and failures in TNS' revisions.

In proactive measures to address these issues, some corporations have turned to ergonomic and spatial interventions while others test shorter workweeks and flexible schedules. Integrating some into larger workplace initiatives - the bulk of which have emerged under the umbrella of a company's sustainability program - are proving effective strategies that question whether TNS is really the next step modern businesses should take when considering organizational sustainability.

\section{Conclusion}

TNS has demanded defense, which, in response, led to journal papers by Robèrt with portions directly addressing misconceptions (Robèrt, 2000). Many surround an ongoing debate about TNS' wider applicability and validity, which could be potentially due to its theorists seemingly treating confirm and apply phases of theory building as unnecessary. They are not.

Future studies need to begin with TNS' revisions in 2017 to determine if they genuinely address employee health, which has already been shown to comprise a substantial component in any contemporary sustainability 
conundrum. Wellness programs augmented TNS in that they began a focus on sustaining human capital by easing certain health-related burdens not addressed by legal statutes. Combined in an ideal manner, an organization might achieve a more holistic state of sustainability than a state reached by subscribing only to one theory like TNS.

As ecological and natural disasters combine with rising direct, and indirect, costs from the chronically ill, new iterations of TNS have refined the theory for wider, more effective applicability. But TNS may still fail to fully take root in a corporate landscape researchers opine will become unrecognizable between today and 2023 - the result of schism likened in magnitude to that spawned from the Industrial Revolution (Gratton, 2016).

Corporations, large and small, are tinkering with alternatives like global goliath Amazon's 30-hour workweek (Weller, 2016). Other companies are limiting time employees spend in sedentary conditions, changing the spatial "neighborhood" in offices (Ying \& Eunhwa, 2014), while others push their preferred program(s) through sustainability efforts in ways not too dissimilar from TNS: "Backers of ergonomics programs need to start leveraging the momentum that is created by sustainability" (Ellison \& Nou, 2011, p. 40). There is little doubt "sustainability" has become both a byword and buzz phrase in the public lexicon.

At a crossroads now, having ignored all but two of four primary theory building phases, some naturally question TNS' own sustainability. Organizations adopting TNS' road to sustainable development should consider its theoretical potholes as well as necessary detours in the face of a silent, but rising, crop of the chronically ill.

\section{References}

Ageing staff pose long-term threat to productivity levels. (2009). Occupational Health, 61(5), 7.

Anderson, R. (1994). Epiphany. Retrieved $\mathrm{http}: / / \mathrm{www}$. interfaceglobal.com/Sustainability/Interface-Story.aspx

Bradbury, H., \& Clair, J. A. (1999). Promoting sustainable organizations with Sweden's Natural Step. The Academy of Management Executive (1993-2005), 13(4), 63-74.

Brundtland, G. H. (1987, March 20). Our common future, from one Earth to one world. Oslo, Norway: Report of the World Commission on Environment and Development. Retrieved from http://www.un-documents.net/our-common-future.pdf

Burns, S. (1999). The natural step: A compass for environmental management systems. Corporate Environmental Strategy, 6(4), 329-342. https://doi.org/10.1016/S1066-7938(00)80049-4

Chronic conditions cause 164 million missed workdays, cost employers $\$ 30$ billion yearly. (2007). $H \& H N$ : Hospitals \& Health Networks, 81(11), 60-61.

Davis, M. (2014, September 3). Radical industrialists: 20 years later, Interface looks back on Ray Anderson's legacy. Retrieved from https://www.greenbiz.com/blog/2014/09/03/20-years-later-interface-looks-back-ray-andersons-legacy

De Greef, M., \& Van den Broek, K. (2004). Report: Making the case for workplace health promotion, analysis of the effects of WHP. European Network for Workplace Health Promotion (ENWHP). Retrieved from http://www.enwhp.org/fileadmin/downloads/report_business_case_01.pdf

Dellwo, A. (2017, December 1). Is Fibromyalgia an autoimmune disease? Retrieved from https://www.verywell.com/is-fibromyalgia-an-autoimmune-disease-716148

Dunning, M. (2015). Finding value in wellness programs. Business Insurance, 49(22), 4.

Ellison, J., \& Nou, D. (2011). Ergonomics hitches a RIDE. Industrial Engineer: IE, 43(9), 40-44.

Ezechieli, E., Ugas, O., \& Aanraad, B. (2017, May 24). The Natural Step International statutes. The Natural Step International. Stockholm, Sweden.

Gratton, L. (2016). Workplace 2025 -- what will it look like? In G. R. Hickman (Ed.), Leading organizations: Perspectives for a new era (pp. 34-45). Los Angeles, CA: Sage Publications.

Holleman, M. (2014, March 25). After 25 years, Exxon Valdez oil spill hasn't ended. CNN.Com. Retrieved from http://www.cnn.com/2014/03/23/opinion/holleman-exxon-valdez-anniversary/index.html

Holmberg, J. (1998). Backcasting: A natural step in operationalising sustainable development. Greener Management International, (23), 30-51. 
Holmberg, J., \& Robèrt, K.-H. (2000). Backcasting from non-overlapping sustainability principles -- a framework for strategic planning. International Journal of Sustainable Development World Ecology, 7, 118.

Hopkinson, N. S., Hart, N., Jenkins, G., Kaminski, N., Rosenfeld, M., Smyth, A., \& Wilkinson, A. (2017). Climate change and lung health: The challenge for a new president. Thorax, 72(4), 295. https://doi.org/10.1136/thoraxjnl-2017-209978

Hoy, D., March, L., Brooks, P., Blyth, F., Woolf, A., Bain, C., ... Buchbinder, R. (2014). The global burden of low back pain: Estimates from the Global Burden of Disease 2010 Study. Annals of the Rheumatic Diseases, 73(6), 968-974. https://doi.org/10.1136/annrheumdis-2013-204428

Is a Healthy Work Force in Danger of Disappearing? (2012). EHS Today, 5(10), 32-32.

Lynham, S. A. (2002). The general method of theory-building research in applied disciplines. Advances in Developing Human Resources, 4(3), 221-241.

Malcolm, T. (1998). Program seeks to nurture planet, profits. National Catholic Reporter, 34(29), 5.

Missimer, M., Robèrt, K.-H., \& Broman, G. (2017a). A strategic approach to social sustainability - Part 1: Exploring the social system. Systematic Leadership towards Sustainability, 140, 32-41. https://doi.org/10.1016/j.jclepro.2016.03.170

Missimer, M., Robèrt, K.-H., \& Broman, G. (2017b). A strategic approach to social sustainability - Part 2: A principle-based definition. Systematic Leadership towards Sustainability, 140, 42-52. https://doi.org/10.1016/j.jclepro.2016.04.059

Missimer, M., Robèrt, K.-H., Broman, G., \& Sverdrup, H. (2010). Exploring the possibility of a systematic and generic approach to social sustainability. Journal of Cleaner Production, 18(10), 1107-1112. https://doi.org/10.1016/j.jclepro.2010.02.024

Munir, F., Randall, R., Yarker, J., \& Nielsen, K. (2009). The influence of employer support on employee management of chronic health conditions at work. Journal of Occupational Rehabilitation, 19(4), 333-344. https://doi.org/doi:http://dx.doi.org/10.1007/s10926-009-9199-7

Nattrass, B., \& Altomare, M. (1999). The natural step for business. Gabriola Island, BC Canada: New Society Publishers.

Nicole, A. (2015, November 11). 10 things I wish my employer understood about working with a chronic illness. Retrieved

from http://themighty.com/2015/11/10-things-i-wish-my-employer-understood-about-working-with-a-chronic-ill ness/

Ny, H., MacDonald, J. P., Broman, G., Yamamoto, R., \& Robèrt, K.-H. (2006). Sustainability constraints as system boundaries: An approach to making Life-Cycle management strategic. Journal of Industrial Ecology, 10(1/2), 61-77. https://doi.org/10.1162/108819806775545349

Paton, N. (2014). Employees with musculoskeletal disorders fear stigma at work. Occupational Health, 66(10), 7.

Robèrt, K.-H. (2000). Tools and concepts for sustainable development, how do they relate to a general framework for sustainable development, and to each other? Journal of Cleaner Production, 8(3), 243-254. https://doi.org/10.1016/S0959-6526(00)00011-1

Robèrt, K.-H., Daly, H., Hawken, P., \& Holmberg, J. (1997). A compass for sustainable development. International Journal of Sustainable Development and World Ecology, 4(2), 79-92. https://doi.org/10.1080/13504509709469945

Robèrt, K.-H., Schmidt-Bleek, B., Aloisi de Larderel, J., Basile, G., Jansen, J. L., Kuehr, R., ... Wackernagel, M. (2002). Strategic sustainable development -- selection, design and synergies of applied tools. Journal of Cleaner Production, 10, 197-214.

Siu, A. M., Hung, A., Lam, A. Y., \& Cheng, A. (2013). Work limitations, workplace concerns, and job satisfaction of persons with chronic disease. Work, 45(1), 107-115. https://doi.org/10.3233/WOR-121550

Swanson, R. A., \& Chermack, T. J. (2013). Theory building in applied disciplines. San Francisco, CA: Berrett-Koehler Publishers, Inc. 
Swanson, R. A., \& Holton III, E. F. (2009). Foundations of human resource development. San Francisco, CA: Berrett-Koehler Publishers, Inc.

Thatcher, A. (2014). Theoretical definitions and models of sustainable development that apply to human factors and ergonomics. Paper presented at the 11th International Symposium on Human Factors in Organisational Design and Management and the 46th Annual Nordic Ergonomics Society Conference, Copenhagen, Denmark. Retrieved from https://www.researchgate.net/publication/265128099

The Interface story. (2016). Interface Global. Retrieved from http://www.interfaceglobal.com/Sustainability/Interface-Story.aspx

United Nations. (2015). Transforming our world: The 2030 agenda for sustainable development (Department of Economic and Social Affairs). New York, NY: United Nations. Retrieved from https://sustainabledevelopment.un.org/post2015/transformingourworld/publication

Upham, P. (2000a). An assessment of The Natural Step theory of sustainability. Journal of Cleaner Production, 8(6), 445-454. https://doi.org/10.1016/S0959-6526(00)00012-3

Upham, P. (2000b). Scientific consensus on sustainability: The case of The Natural Step. The Sustainable Development Journal, 8(4), 180-190.

Waldron, D. (2005). A new education: Strategic leadership towards sustainability. Presented at the Seminar on Education for Sustainable Development, Stockholm, Sweden.

Waldron, D., Byggeth, S., Ny, H., Broman, G., \& Robèrt, K.-H. (2004). Structured comprehension for systems thinking, learning and leadership towards sustainability. Blekinge Institute of Technology, Sweden.

Weller, C. (2016, September 6). Here's why Amazon's new 30-hour workweek is such a great idea. Business Insider. Retrieved from http://www.businessinsider.com/amazon-30-hour-workweek-great-2016-8

White, C. M. (2015). Proactive Ergonomics. Professional Safety, 60(6), 69-73.

Ying, H., \& Eunhwa, Y. (2014). Building spatial layout that supports healthier behavior of office workers: A new performance mandate for sustainable buildings. Work, 49(3), 373-380. https://doi.org/10.3233/WOR-141872

Zimek, M., \& Baumgartner, R. (2017). Corporate sustainability activities and sustainability performance of first and second order. Paper presented at the 18th European Roundtable on Sustainable Consumption and Production Conference (ERSCP 2017), Skiathos, Greece. Retrieved from https://www.researchgate.net/publication/320612163_Corporate_sustainability_activities_and_sustainabilit y_performance_of_first_and_second_order

\section{Copyrights}

Copyright for this article is retained by the author(s), with first publication rights granted to the journal.

This is an open-access article distributed under the terms and conditions of the Creative Commons Attribution license (http://creativecommons.org/licenses/by/4.0/). 